\title{
FATORES QUE INFLUENCIAM O ENDIVIDAMENTO E A INADIMPLÊNCIA NO SETOR IMOBILIÁRIO DA CIDADE DE TORITAMA-PE À LUZ DAS FINANÇAS COMPORTAMENTAIS
}

\author{
W. G. L. LUCENA ${ }^{1}{ }^{*}$, J. M. A. SANTOS ${ }^{2}$, J. T. ASSIS ${ }^{2}$ e M. C. SANTOS ${ }^{2}$ \\ ${ }^{1}$ Universidade Federal da Paraíba - UFPB \\ FAVIP \\ wdlucena@yahoo.com.br
}

Artigo submetido em setembro/2012 e aceito em dezembro/2014

DOI: $10.15628 /$ holos.2014.1084

\section{RESUMO}

Entender a dinâmica financeira, num contexto de crises econômicas mundiais, onde o incentivo ao consumo se contrasta com os elevados índices de endividamento e inadimplência existentes; não é tarefa fácil. Neste sentido, busca-se com a realização deste trabalho executar um estudo a respeito de quais os fatores que influenciam os altos índices de endividamento e inadimplência no setor imobiliário de loteamentos da cidade de Toritama - PE, a luz das Finanças Comportamentais. Para isto, utilizou-se uma pesquisa de caráter descritivo com os proprietários de lotes, realizada através de análises quantitativas, onde os dados foram mensurados por meio de estatística descritiva em forma de tabelas e percentuais para melhor análise, com uma amostra de 200 proprietários. Como resultado percebeu-se que os principais fatores que ocasionam o endividamento destes indivíduos são: baixa renda familiar, sazonalidade de mercado, falta de planejamento financeiro e desemprego. Percebeu-se também a influência dos vieses cognitivos, otimismo e excesso de confiança, em apenas uma parcela dos entrevistados.

PALAVRAS-CHAVE: Finanças comportamentais, Endividamento, Inadimplência, Setor Imobiliário de loteamentos.

\section{FACTORS THAT INFLUENCE THE DEBT AND THE DEFAULT IN REAL ESTATE SECTOR OF THE TORITAMA CITY (PE) IN LIGHT OF THE BEHAVIORAL FINANCES}

\begin{abstract}
Understand the financial dynamics in the context of global economic crises, where the incentive to consumption contrasts with the high levels of existing debt and default, is no easy task. In this sense, we seek to perform this work a study on the factors influencing the high levels of indebtedness and defaults in real estate subdivisions of the city of Toritama - PE, light of Behavioral Finance. For this, we used a descriptive research with the owners of lots held by quantitative
\end{abstract}

analysis, where the data were measured by means of descriptive statistics in tables and percentages for better analysis, with a sample of 200 owners. As a result it was found that the main factors that cause the indebtedness of these individuals are: low income, seasonality of the market, lack of financial planning and unemployment. We also noticed the influence of cognitive biases optimism and overconfidence in one of the interviewees.

KEYWORDS: Behavioral finances, Debt, Breach of contract, Real estate Section of lots divisions. 


\section{INTRODUÇÃO}

O endividamento está crescendo no mundo todo e embora não seja um problema exclusivo do Brasil, exige uma atenção especial mediante a sua amplitude FERREIRA (2009). Este fato pode ser ocasionado pela falta de conhecimento e planejamento financeiros, por motivos implícitos ao indivíduo em razões sociais e psicológicas como explica as finanças comportamentais ou por fatores externos sob a ótica de desemprego, queda na renda, problemas de saúde; entre outros.

Além disso, conforme lembra Casado (2001) apud Borsato et. al., (2009a), o consumo está cada vez mais incentivado por publicidades agressivas, geradoras de falsas necessidades.

Ou seja, com as inúmeras facilidades e ofertas que os meios de comunicação em massa e a publicidade oferecem, os consumidores criam falsas necessidades objetivadas pelo desejo de "ter" e "ser" que a sociedade capitalista impõe.

Porém nem sempre, estes indivíduos estão preparados para assimilarem tanta oferta e facilidades, acabando por consequência, endividados e até inadimplentes.

Pois como afirma Borsato et al., (2009a), diante do consumo excessivo, muitos indivíduos contraem dívidas, comprometendo uma parcela significativa de suas rendas, tornando-se em muitos casos inadimplentes por não conseguir cumprir com os seus compromissos financeiros.

O endividamento, no entanto, ocasiona sérias consequências tanto para o indivíduo, podendo até levá-lo a situações extremas como o suicídio, como para a saúde financeira das empresas.

Diante desta realidade, compreender os fatores comportamentais, cognitivos e emocionais que orientam as decisões dos indivíduos não é tarefa fácil, pois envolvem subjetividades e incertezas; no entanto são fundamentais para justificar as mesmas. (MALLMANN et al., 2009)

Na Sociedade nos dias atuais o consumo é caracterizado pelo individualismo, onde as pessoas valem mais pelo o que tem e não pelo o que são. (COSTA, 2004).

Sendo vistas como um potencial de compra, elas acabam perdendo os seus referências sociais, "os espelhos da formação" de sua identidade à medida que são invadidas por um mar de quinquilharias de utilidade cada vez mais duvidosa, que apenas contribuem para sua desorientação. (COSTA, 2004).

Diante deste cenário em que o consumo se contrapõe em muitas vezes aos valores éticos e morais, diversas correntes como a psicologia, a economia e as finanças comportamentais vêm intensificando os seus estudos sobre o comportamento dos indivíduos em relação às decisões financeiras frente às atitudes de comprar, vender, consumir, poupar e se endividar. (MALLMANN et. al., 2009).

No entanto, conforme Macedo Jr. (2003) apud Borsato et al. (2009a) o interesse em analisar o comportamento humano no processo de tomada de decisões financeiras, remota há mais de um século pela psicologia cognitiva que é parte integrante das teorias de finanças comportamentais e concentra-se em estudar os processos da mente, baseado em como as percepções, convicções e modelos mentais do próprio decisor influenciam e interferem na ação e 
na decisão escolhida. Ou seja, como as emoções e os fatores psicológicos podem influenciar em suas escolhas.

Vitt (2004) apud Zerrenner (2007) corrobora com este pensamento ao afirmar que a decisão de consumo é afetada por aspectos psicológicos, físicos, e por valores que estão baseados em sentimentos e emoções.

Esta corrente, no entanto, se contrapõe aos pressupostos simplificadores das teorias tradicionais de finanças, cujo paradigma central é a racionalidade dos agentes econômicos, onde os indivíduos (decisores) mostram-se aptos e com conhecimento absoluto de todas as opções disponíveis da ação (SIMON apud BORSATO et al., 2009a).

Além dos fatores comportamentais as diversas facilidades com que os consumidores têm acesso ao crédito também se caracterizam como fator essencial ao consumo excessivo. Este, porém, leva o indivíduo a comprometer grande parte de sua renda familiar ficando endividado e em muitos casos inadimplentes.

Segundo pesquisa realizada por psicólogos do Reino Unido, mas que facilmente poderia se enquadrar a nossa realidade, existem duas categorias de devedores: aqueles que se endividam por falta de recursos (em função, por exemplo, de aumento de filhos, desemprego ou emprego precário) e os que estão endividados, não por apresentarem tanta dificuldade financeira em pagar suas contas, mas por competência insuficiente em administrar seu dinheiro, ou insuficiência de renda. (FERREIRA, 2009)

Kotler e Keller (2006) relacionam ainda fatores como idade, estágio no ciclo de vida, ocupação, personalidade, auto-imagem além de transições ou mudanças na vida decorrentes do casamento, nascimento de filhos, divórcios, viuvez como características que tem impacto direto sobre o comportamento do consumidor face às decisões financeiras.

Um sujeito endividado, no entanto, torna-se mais vulnerável a incidentes pessoais como separação, desemprego, problemas de saúde, podendo levar, no limite, a que este indivíduo se torne impossibilitado de cumprir suas obrigações. (ZERRENNER, 2007).

O endividamento, portanto, não só afeta ao indivíduo e a sua família, mas também às organizações, pois como enfatiza Mallmann et al., (2009) estudar os fatores que influenciam o endividamento se mostra essencial para a área financeira uma vez que a relação desejo necessidade - consumo- endividamento - inadimplência se torna de interesse das empresas, pois afetam todo o ciclo operacional destas; podendo implicar inclusive um desajuste de liquidez e aumento do risco.

Portanto, fica evidenciada a importância de um aprofundamento nos estudos sobre os fatores que influenciam o endividamento e a inadimplência dos indivíduos à luz das finanças comportamentais. A partir desse pressuposto surge a seguinte indagação que norteará este trabalho: Quais os fatores que influenciam o endividamento e o alto índice de inadimplência nos setores econômicos? Cabe explicar que nesta pesquisa o setor econômico analisado foi o imobiliário com atuação específica em loteamentos na cidade de Toritama - PE. E tem como objetivo identificar quais são esses fatores.

Partindo desse pressuposto, se buscou elaborar um artigo dividido em 05 etapas, apresentadas a seguir: 
$\mathrm{Na}$ primeira, serão apresentados conceitos relativos às finanças comportamentais; buscando-se evidenciar através da situação problema que o estudo da mesma é de extrema importância para explicar as "anomalias" que os mercados apresentam; pois acredita-se que as finanças comportamentais embora seja um tema pouco conhecido, veio para quebrar paradigmas no tocante a importância de se verificar os aspectos psicológicos que afetam as decisões financeiras dos indivíduos, mostrando que estes possuem racionalidade limitada diferentemente como pregavam as teorias tradicionais de finanças. Além das Finanças Comportamentais, serão tratadas questões sobre endividamento e inadimplência já que esses aspectos parecem ser determinantes não só para a saúde financeira dos indivíduos como das empresas.

Ainda na primeira etapa foi apresentado o objetivo que norteia este estudo bem como os motivos que desencadearam a importância deste trabalho.

A segunda parte está composta do referencial teórico, onde foi apresentado um estudo mais detalhado sobre os temas que são objetos desse trabalho, destacando: os fatores que geram endividamento e consequentemente inadimplência, as Finanças Comportamentais e seus vieses cognitivos e o setor econômico estudado que é o imobiliário com atuação específica em loteamentos de condição horizontal.

A terceira etapa mostrou a metodologia que foi utilizada, evidenciando dentre outros aspectos o instrumento de coleta de dados, a natureza da pesquisa, a delimitação da amostra.

A quarta etapa tem-se a apuração dos resultados obtidos. Por fim, na quinta e última etapa serão apresentadas as principais considerações finais com as indicações para futuras pesquisas.

\section{FINANÇAS COMPORTAMENTAIS (CONCEITO E EVOLUÇÃO)}

É cabível de explicação que a palavra Finanças, segundo o Novíssimo Dicionário de Economia, (1999); corresponde a uma área da economia que engloba os ramos de atividade es processos relacionados com a gestão de recursos públicos, privados, dinheiro, crédito, títulos, ações e obrigações pertencentes ao Estado, às empresas e aos indivíduos. Ou seja, as finanças constituem representações simbólicas e indiretas de atividades econômicas reais que afeta direta e indiretamente não só os indivíduos como o mercado em geral.

A evolução da área de finanças pode ser estruturada em Finanças Tradicionais; Finanças Modernas e as Finanças Comportamentais. (BORSATO, PIMENTA e RIBEIRO, 2009b).

As Finanças Tradicionais estão constituídas a partir de uma abordagem microeconômica neoclássica cujo paradigma central é a racionalidade dos agentes econômicos. As Finanças Modernas, fundamentada no modelo financeiro da Hipótese de Eficiência dos Mercados (HEM) fora a idéia central da área de finanças por quase 40 anos; essa teoria fundamenta-se na utilidade esperada e nas expectativas racionais, considerando que os indivíduos ordenam de forma lógica suas preferências, buscando maximizar a "utilidade" de suas escolhas. No entanto, nenhumas destas teorias seriam capazes de explicar diversos fatos decorrentes de anomalias de mercado provocadas dentre outros fatores pelas crises financeiras, os quais evidenciam que os agentes econômicos apresentam limitações e não são totalmente racionais. (BORSATO et al., 2009a; BORSATO, PIMENTA e RIBEIRO, 2009b). 
Milanez, (2001) argumenta que tais limitações, intrínsecas à natureza humana, devem ser incorporadas à análise econômica como extensão natural dos modelos atuais, uma vez que a evidência sugere tanto que os agentes são capazes de cometer certa variedade de erros sistemáticos como também desvios que causam importantes implicações econômicas.

Diante deste cenário, surge a Teoria das Finanças Comportamentais que corresponde a um novo campo de estudo nascido da necessidade de pensadores sociais, juristas, economistas e psicólogos de acrescentar um enfoque mais abrangente à economia, não como ciência, mas sim como modelos e teorias emanadas, visto que, estas não mais se mostravam suficientes para explicar os fenômenos econômicos que são sempre influenciados pela participação, e conseqüentemente pela limitação humana. (MALMANN, et.al, 2009).

Segundo Milanez (2001), as Finanças Comportamentais são um programa de pesquisa que vem ganhando crescente reconhecimento no mundo acadêmico e fora dele. Seu traço distintivo é a incorporação de conceitos de outras áreas (como psicologia e sociologia) e a Economia para explicar as decisões financeiras dos indivíduos.

Borsato et.al., (2009a) destaca ainda que além das Finanças Comportamentais serem um novo campo de estudos que se contrapõe a racionalidade dos modelos econômicos tradicionais, suas vertentes buscam identificar como as falhas cognitivas podem influenciar o processo de tomada de decisões dos indivíduos.

Ou seja, as Finanças Comportamentais vieram quebrar os paradigmas das abordagens tradicionais da economia ao procurar introduzir aspectos psicológicos e sociológicos no comportamento dos indivíduos face as suas decisões financeiras; esses aspectos porém são incompatíveis aos presságios dos modelos tradicionais.

Borsato, Pimenta e Ribeiro (2009b) acrescentam ainda que o Tema Finanças Comportamentais têm sido um dos assuntos mais polêmicos do estudo de Finanças, pois trata do comportamento humano diante do processo decisório de investimento.

Os precursores desse estudo foram os psicólogos Amos Tversky e Daniel Kahaneman, que dedicaram parte de seus trabalhos para a análise do comportamento dos investidores; servindo de alicerce para os estudos realizados até os dias atuais. Em seguida os estudiosos Richard Thaler e Robert Shiller vieram afirmar a eficácia dessas análises. (BORSATO, PIMENTA e RIBEIRO, 2009b).

O recente prêmio Nobel de Economia de 2002, concedido a Daniel Kahaneman por seus trabalhos em Finanças Comportamentais mostra que essa linha de pensamento vem ganhando cada vez mais espaço no meio acadêmico, estabelecendo-se definitivamente como a teoria que desafia o paradigma imposto pelas teorias tradicionais de economia. As crescentes produções acadêmicas nos Estados Unidos e Europa, bem como a grande aceitação por parte de autores e defensores de presságios neoclássicos destacam a importância e atualidade do tema. No Brasil, porém, as pesquisas sobre Finanças Comportamentais ainda são bastante incipientes. Thaler (1993) apud Milanez, (2001).

Contudo, embora não exista um modelo único de Finanças Comportamentais; ela vislumbra a possibilidade de aperfeiçoar o modelo moderno de finanças na proporção que incorpora os conceitos de racionalidade limitada e os reflexos do comportamento humano. (BORSATO et. al, 2009a). 


\section{OS VIESES COGNITIVOS E AS FINANÇAS COMPORTAMENTAIS}

Em seus estudos Tversky e Kahaneman (1979) apud Souza (2003) desenvolveram a teoria da perspectiva ou (Prospect Theory); criada e estudada pelas finanças comportamentais esta teoria vem explicar os desvios da Teoria da Utilidade Esperada, uma vez que esta, não descreve precisamente como os indivíduos avaliam suas opções de escolha. Mais adiante em um novo estudo, os autores perceberam que em função de imperfeições na percepção humana, mudanças de perspectiva podem modificar o tamanho relativo dos objetos e o nível de desejo de cada opção. (TVERSKY e KAHANEMAN, 1981; apud SOUZA, 2003)

Souza, (2003) destaca ainda, que a aparente falta de racionalidade na tomada de decisões pode ser parcialmente explicada pela forma com que essas alternativas são estruturadas. Além disso, as normas, os hábitos e as características pessoais de quem toma a decisão também podem enviesar a escolha das alternativas. O autor enfatiza, portanto, a influência comportamental nas decisões dos indivíduos.

Assim sendo, a teoria das Finanças Comportamentais parte do pressuposto de que os agentes não conseguem tomar decisões racionais a todo instante (têm problemas de vieses no processo cognitivo e limites ao aprendizado), e arbitradores racionais são limitados em seus esforços para eliminar tais distorções. (MILANEZ, 2001)

Borsato et. al., (2009a) corrobora com este pensamento ao afirmar que o estudo sobre finanças comportamentais postula que alguns fenômenos financeiros são mais bem entendidos, usando modelo nos quais os agentes não são completamente racionais podendo ser influenciados por ilusões cognitivas. Estas, porém, tem implicações diretas no comportamento dos tomadores de decisões.

Borsato, Pimenta e Ribeiro (2009b) complementam evidenciando que os estudos do comportamento humano frente à tomada de decisões financeiras denotam a possibilidade de que as emoções e erros cognitivos dos indivíduos influenciem essas decisões provocando alterações no mercado.

Belhot (2008) afirma ainda que cada pessoa possua habilidades individualizadas de aprendizagem, e cada indivíduo tem uma forma diferente de entender uma informação, ou seja, as habilidades cognitivas dos indivíduos são distintas. Os estudos sobre os estilos cognitivos dos indivíduos, no entanto, têm suas origens nos estudos sobre cognição humana que pode ser definida com um campo da psicologia - parte integrante das finanças comportamentais- e que possui como objetivo central o estudo do comportamento humano, a compreensão dos processos mentais e a procura pelas causas e conseqüências.

Segundo Kahneman e Piepe (1998) apud Borsato et. al.,(2009a), ilusão cognitiva é a tendência humana de cometer erros sistemáticos no processo de tomada de decisão.

Fuller (1998) apud Borsato et. al.,(2009a), classifica as ilusões cognitivas em dois grupos: as ilusões resultantes da utilização de regras heurísticas nos processos de tomada de decisão (Tversky e Kaheneman, 1974) e as ilusões causadas pela adoção de estruturas mentais descritas na teoria do prospecto (KAHNEMAN e TVERSKY, 1979 apud BORSATO et. al., 2009a)

Segundo Tversky e Kahneman (1974) apud Borsato et.al.,(2009a) heurísticas são atalhos mentais que tornam mais leve a carga cognitiva de tomar decisões, mas que podem conduzir a 
vieses no processo de decisão,ou seja, a simplificação da estratégia de processamento da informação, pode ocasionar muitas vezes uma distorção na maneira como os indivíduos percebem a realidade.

Tversky e Kahneman (1974) apud Borsato et. al., (2009a) ainda afirmam que, existem três ilusões cognitivas causadas por regras heurísticas: a da disponibilidade que enfatiza a forte tendência que os indivíduos têm em concentrar sua atenção em um fato particular que está mais presente em sua mente e que facilmente poderá vir a sua memória ao invés da situação completa; a heurística da representatividade em que os indivíduos julgam um evento incerto de acordo com o quanto ele é parecido ou representativo em relação à população da qual ele se origina e de acordo com os aspectos relevantes do processo pelo qual é gerado, bem como o acaso. E a Heurística da ancoragem e ajuste que acontece quando um indivíduo tem que fazer uma estimativa a começar pelo um valor inicial que é reajustado para revelar a resposta final. (MACEDO Jr., 2003 apud BORSATO et. al. 2009a)

Bazerman (2004) apud Borsato et.al., (2009a), ressaltam que a utilização da heurística de ancoração e ajustamento leva ao aparecimento de vieses cognitivos como: Ajuste insuficiente da âncora, Efeitos conjuntivos e disjuntivos e Excesso de Confiança.

Este trabalho enfatiza os vieses Excesso de Confiança e Otimismo como forma de verificar até que ponto eles influenciam no julgamento que as pessoas fazem sobre eventos e sobre si mesma face suas decisões financeiras.

Milanez (2001) enfatiza que é intrínseco ao indivíduo pensar que está acima da média em várias coisas e acontecimentos como, por exemplo, achar que é mais inteligente e mais capaz que o outro, mais amigável, mais comunicativo etc, e que este comportamento está ligado às atitudes de defesa do ego (necessidade que se tem de manter a harmonia entre as crenças e atitudes). Ou seja, na maioria das vezes o indivíduo acredita que têm habilidades superiores a média da população, que o seu sucesso é devido aos seus conhecimentos e habilidades, que acontecimentos ruins estão relacionados a fenômenos não controláveis e que seus erros têm participação direta de outras pessoas.

Lovallo e Kahneman (2003) apud Borsato et. al., (2009a), enfatizam que o Otimismo gera mais entusiasmo que realismo, o que dificulta uma avaliação mais adequada da realidade e que essa ilusão cognitiva pode fazer com que os indivíduos (investidores ou não) sejam menos resistentes quando confrontados com situações mais difíceis e desafiadoras.

No entanto, a idéia de que os agentes econômicos são confiantes em excesso é bastante antiga, como já enfatizava Adam Smith. (MILANEZ, 2001).

\section{ENDIVIDAMENTO: CONCEITOS E CONSEQUÊNCIAS}

O alto índice de pessoas endividadas vem estimulado o surgimento de vários estudos no intuito de identificar os fatores que levam os indivíduos a este estado. Segundo Ferreira, (2009), o endividamento está crescendo no mundo todo e em função de sua amplitude exige uma atenção rápida e eficaz.

Para o Centro de Estudos Sociais da Faculdade de Economia da Universidade de Coimbra (2002) o endividamento é o saldo devedor de um indivíduo podendo este resultar apenas de uma dívida ou mais de uma simultaneamente. 
Para Katona (1975 apud MALMANN et.al., 2009) precursor do estudo sobre endividamento na ótica econômica/psicológica existem três razões que explicam porque uma pessoa pode gastar mais do que ganha: a primeira é quando o indivíduo pertence a uma classe social de baixa renda onde nem sequer consegue cobrir despesas essenciais; a segunda equivale a pessoas de alta renda, combinada com um forte desejo de gastar e a terceira razão corresponde a falta de vontade em economizar independente de que nível social a pessoa faça parte.

Segundo a pesquisadora e psicóloga Márcia Tolli (2009, p.1). "o endividado é aquela pessoa que se joga para um risco". Ela não sabe como vai pagar, mas mesmo assim compra.

A autora classifica os endividados em três categorias:

- Ativo: é aquela pessoa que está constantemente contraindo dívidas e alega que teve imprevisto;

- Sobreendividado: é o equivalente a um falido. Estoura o cheque especial, realiza inúmeras parcelas no cartão de crédito, além de empréstimos;

- Passivo: este é o endividado que realmente passou por um imprevisto, seja ele doença, acidentes, desemprego, morte ou separação.

Fazendo um paralelo entre as três razões que levam um indivíduo a endividar-se e as categorias de endividados acima citadas, percebe-se que:

Os indivíduos que contraem dívidas por falta de recursos, onde suas despesas são mais altas que seus recebimentos em função muitas vezes de desemprego, grande número de filhos, emprego precário; como explica a razão $\mathrm{n}$ 0 01 se enquadram na categoria de endividado passivo, ou seja, aquele que está passando ou passou por alguma dificuldade econômica e por esta razão não consegue saldar sua dívidas.

Já os que não teriam tanta dificuldade em pagar suas contas por se encontrarem em uma classe social mais favorecida, mas que mesmo assim estão endividados, como enfatiza a razão no 02 para o endividamento, se enquadram na categoria de endividado ativo, isto é, por ser bastante consumista e por não possuir a competência necessária para administrar seu dinheiro, acabam endividados.

Por fim, o indivíduo que se enquadra na categoria de sobreendividado é também uma pessoa bastante consumista, mesmo não possuindo recursos suficientes que supram seus "desejos" de comprar; levando-o a contrair inúmeras dívidas e em todos os meios possíveis como cartão de crédito, cheque, empréstimos, entre outros. (Razão no 03 para as causas do endividamento)

Ferreira (2009) destaca ainda, a aceitação social, a socialização econômica; a comparação social; o estilo individual ou familiar de administrar as finanças pessoais ou os pequenos negócios; os comportamentos ligados ao consumo como saber definir o que é essencial ou supérfluo, além de atitudes ante a questão do endividamento decorrentes do gênero, faixa etária e religião como variáveis que também podem estabelecer a causa do endividamento.

Além desses aspectos já enfatizados, a sociedade atual valoriza o ser pela quantidade de bens e riquezas ele possui, onde o consumo é cada vez mais incentivado por publicidades agressivas que geram falsas necessidades o que leva a pessoa humana ser vista como um potencial de compras. (CASADO, 2001 apud ZERRENNER, 2007). 
Consalter (2005, p. 156 apud BORSATO et al., 2009a) afirmam que:

O consumidor precisa enfrentar três diferentes batalhas contra o crédito, uma, contra si mesmo e seu desejo de ter; outra contra a avalanche virtual da publicidade via televisão, internet, etc.; e, uma terceira, contra o ataque físico, quando, caminha pelo centro da cidade, e é incessantemente abordado por homens e mulheres de panfletos em punho.

A todo instante tem que se estar lutando contra o chamariz de ofertas e facilidades que levam os indivíduos a contraírem dívidas. No entanto, nem sempre essas pessoas estão preparadas para enfrentar tal situação, acabando endividadas e muitos casos inadimplentes.

A inadimplência, porém, segundo o Minidicionário Ediouro da língua portuguesa (2000) corresponde a s.f. Falta de cumprimento de um contrato ou de qualquer de suas condições; descumprimento, inadimplência.

Ela é um estágio em que o indivíduo deixa de saldar os seus compromissos financeiros, diferentemente do endividamento, pois o indivíduo pode contrair muitas dívidas mais continuar adimplente, isto é, com capacidade de honrar suas dívidas.

Zerrener (2007) enfatiza que um sujeito endividado ou inadimplente, no entanto, torna-se mais vulnerável a incidentes pessoais, como problemas de saúde, separação, desemprego, entre outros, podendo levar, no limite, a que este indivíduo se torne impossibilitado de cumprir suas obrigações e até busque o suicídio.

O endividamento, porém não só afeta os indivíduos, mas também a economia, já que afeta o ciclo operacional das empresas, podendo implicar inclusive em um desajuste de liquidez e aumento do risco. (RIBEIRO et. al., 2009).

Ferreira, (2009) complementa afirmando que a inadimplência provoca consequências nos créditos concedidos e na viabilidade das operações financeiras e econômicas de microcrédito, pois o não pagamento por parte do tomador prejudica o fluxo de caixa das Instituições micro financeiras (IMF's), inviabilizando sua capacidade de realizar novos empréstimos.

Além disso, a inadimplência dos micros-empreendimentos e das pequenas unidades produtivas tomadoras de microcrédito pode penalizar a credibilidade dos futuros tomadores de recursos, caso não seja identificado e separado os clientes de risco elevado daqueles de baixo risco.

Verifica-se, portanto, que compreender os fatores comportamentais que orientam as decisões financeiras embora não seja tarefa fácil é de extrema importância uma vez que afetam não só os indivíduos como também o mercado seja ele em que segmento se enquadrar.

\section{O MERCADO IMOBILIÁRIO}

O imóvel, como diz o nome é um ativo que conjuga segurança com rentabilidade menor, mas constante, aliada a uma liquidez relativa, já que sempre haverá compradores dispostos a adquirir o chamado bem de raiz, imóvel, que passa de geração para geração. (GONÇALVES e REYDON, 2002). 
Segundo Gonçalves e Reydon (2002), o processo de urbanização acompanhou a industrialização do país, que se unificou de forma significante entre os anos de 1940 a 2000, quando a população na área urbana aumentou de 10.891.000 para 137.953.959 habitantes, dados que revelam um crescimento aproximado de $126,67 \%$.

No entanto, esta urbanização aconteceu de maneira caótica, resultando em uma sociedade complexa, ocupacional, socialmente diversificada, unificada, mas heterogenia, segmentada e completamente desigual. Este aumento da demanda pela terra urbanizada também refletiu nos preços das terras. (GONÇALVES e REYDON, 2000).

Gonçalves e Reydon (2002), ainda afirmam que, um empreendimento imobiliário pode ser dividido em loteamentos que podem ser rurais ou urbanos. O que os distingue, é a finalidade do empreendimento, independentemente da localização. Na mesma vizinhança podem aparecer quatro tipos de loteamentos, são eles: o legal, o irregular, o clandestino e o grilado. 0 loteamento legal está de acordo com todas as especificações físicas e burocráticas. O loteamento irregular é adquirido e registrado por seu empreendedor imobiliário, mas violam de alguma forma as regras de parcelamento da terra. O loteamento clandestino não é registrado no cartório de imóveis, apesar de a terra ser de posse legítima do empreendedor. Por fim, o loteamento grilado é vendido por um grileiro que se diz titular da terra, e faz uma série de artimanhas.

Para Bernal (2002), a determinação dos preços de um mercado de terras está diretamente relacionada com as tendências macroeconômicas e com as condições da cidade local, sendo imprescindível a integração entre as variáveis financeiras do mercado geral e local uma vez que diferentes regiões têm preços crescentes ou decrescentes e em velocidades diferentes; ou seja, é a conjuntura econômica que define preços dos imóveis.

\subsection{Setor Imobiliário no Brasil}

Para Gligio (1998), o setor imobiliário é um dos ramos do imenso mercado da construção civil. Trata-se do segundo segmento do país, ficando atrás apenas da indústria de transformação que engloba os setores automobilísticos, petroquímicos e metalúrgicos.

Para Bernal (2002), a dinâmica deste setor se associa à estruturação interna das cidades, em que é através do Capital que se desenvolve o espaço geográfico, se organiza os investimentos privados no ambiente construído, em especial àqueles destinados às habitações. Ao se adquirir uma habitação, na mesma transação, se adquire uma série de atributos associados na vida urbana, ou seja, modificações do empreendimento, tais como: meio de interação social, facilidades de acesso a outras atividades urbanas, lazer, comércio em geral, entre outras.

Segundo dados da Fundação Getúlio Vargas (FGV) - Instituto Brasileiro de Economia, no ano de 2007 o ICC (Índice de Confiança do Consumidor) contribuiu para o crescimento do país, impulsionando a confiança dos investidores imobiliários. Nos dias atuais acredita-se que o mercado imobiliário vive um bom momento, graças à economia estável. Fernando Garcia, economista da FGV que coordenou estudos sobra o crédito imobiliário no Brasil, afirma que o investimento das famílias até 2010 deve girar em torno de 5,3\% do Produto Interno Bruto (PIB).

De acordo com a Revista Eletrônica de Jornalismo Científico (2007), o diretor executivo do sindicato da habitação, Celso Petrucci é cauteloso em dizer que o Brasil está vivendo o "BOOM Imobiliário", para ele o que acontece é que o país ficou praticamente sem créditos imobiliários 
por aproximadamente quinze anos. A partir de 2002, e principalmente 2004, foram que os créditos imobiliários passaram a ser atrativos aos bancos privados e com a estabilidade econômica do país a concessão de créditos tornou-se mais segura tanto para quem toma quanto para quem concede.

Uma maior oferta de imóveis no mercado, aliado ao bom momento econômico no país, pode sugerir a probabilidade do Brasil criar a chamada "Bolha Imobiliária" como aconteceu com os Estados Unidos, que em 2001 teve um desenvolvimento acelerado e em 2005 o apogeu, onde a expectativa de valorização dos imóveis aumentou significamente os investimentos do setor. As empresas de financiamento especializadas começaram então a liberar empréstimos para o segmento, porém sem garantias de recebimento. Neste momento, aconteceu o colapso na economia do país. Colapso este que ocasionou sérios problemas econômicos mundiais, não só para o setor em questão, mas para todas as esferas da economia, em umas com maior magnitude que outras. (REVISTA ELETRÔNICA DE JORNALISMO CIENTÍFICO, 2007).

No entanto no Brasil, a crise econômica no setor imobiliário não sofreu grandes impactos, e a estimativa é continuar com os bons resultados, uma vez que os mercados de imóveis vêem de um excelente momento, sendo assim, o menos atingido com a crise Americana. Este fato deve-se a consolidação do Brasil no mercado, com uma legislação rigorosa que regulamenta as linhas de crédito evitando a retração dos empréstimos.

Além disso, as próprias características do Brasil o favorecem, uma vez que possui uma vasta extensão territorial e populacional; esses aspectos, agregados ao dinamismo e ao processo de transformação da construção civil, trouxeram tanto investidores nacionais, quanto internacionais. Esta elevação na atratividade no setor deve-se ainda a fatores como: estabilidade macroeconômica (ampliação do crédito governamental e a demanda de mercado por novos imóveis), as mudanças institucionais no setor (redução dos custos das transações e dos riscos dos empreendimentos), forte entrada de capital estrangeiro com ou sem parcerias e a captação de recursos na Bovespa- Bolsa de Valores do estado de São Paulo- o que tem exigido maior transparência e eficiência das empresas do setor. Não há dúvidas, portanto, que o mercado se sofisticou, porém atuar nele ficou mais difícil, já que a conjuntura do mercado global traz uma série de desafios para as organizações. (GONÇALVES, 2002).

No entanto, a compra de um imóvel não só é fruto de transações financeiras, mas também, de um envolvimento emocional já que normalmente abrange o objetivo de vida de muitos indivíduos que sonham em obter a sua casa para uma melhor qualidade de vida.

\subsection{O Setor Imobiliário em Toritama}

Inicialmente a cidade de Toritama sobrevivia da agricultura, no entanto, por encontrar-se no polígono das secas este segmento não evoluiu. Como opção, o município optou, da década de 30 até final dos anos 70, pela indústria de calçados, a exemplo da vizinha Caruaru; contudo com a crise do petróleo ocorrida na época, os preços da matéria-prima para a fabricação do calçado como o solado de borracha, o curvim (imitação de um couro) e cola - todos, produtos do petróleo - ficaram absurdamente caros. Além disto, crescia o mercado de calçados de plástico e tênis do Sul/Sudeste. Então os empresários locais então, tiveram de optar por um segmento mais rentável. (DIÁRIO DE PERNAMBUCO, 2004). 
À época, dos anos 1970 a 1980 a coqueluche era a calça do tipo US TOP, produzida em tecido rústico e sem requerer grandes especializações. Assim, a partir do final dos anos 70 e início dos anos 80, a cidade especializou-se na produção de Jeans. TOPEIRO era o nome popular daqueles que produziam calças US TOP. Com o passar do tempo as indústrias locais aperfeiçoaram seus processos produtivos. Um fato pitoresco para a cidade é o de que o jeans antes de ser comercializado, atendendo as exigências atuais do mercado, requer que o produto seja lavado - o que resultou no aparecimento de muitas lavanderias - apesar da grande falta d'água que sofre a região. Muitas lavanderias utilizam a água extraída do rio Capibaribe e para ele devolvem seus efluentes, provocando muita poluição. Tentando evitar a agressão do meio ambiente, existem iniciativas do Sindicato das Indústrias do Vestuário do Estado de Pernambuco (SINDIVEST-PE / BFZ) na implantação de estações de tratamento de efluentes das lavanderias A indústria e o comércio local utilizam mão-de-obra da própria cidade e de cidades vizinhas. Segundo dados não oficiais, $40 \%$ desta mão-de-obra é oriunda dos municípios vizinhos, visto que toda a mão-de-obra disponível na cidade já estar envolvida na indústria de confecção. (SEBRAE, 2003).

Este fato fez despertar em muitos empresários a promissora oportunidade de negócios do setor imobiliário de loteamentos. Atualmente segundo dados da secretaria Municipal de Tributos da Cidade, existem 30 loteamentos registrados na Prefeitura deste município. No entanto, segundo o Cartório Único de Registros apenas 04 encontram-se legalizados, ou seja, com escritura da área registrada em cartório.

Gonçalves (2002) enfatiza que um loteamento é considerado legal quando está de acordo com todas as especificações físicas e burocráticas. Visando, portanto, fugir da informalidade bastante presente na cidade, optou-se realizar este estudo apenas com os loteamentos considerados legais.

A seguir será apresentado um quadro com algumas características dos loteamentos pesquisados. Como forma de preservar a identidade dessas empresas optou-se por denominá-las de Loteamento A, Loteamento B, Loteamento C, e Loteamento D.

Quadro 1- Características das Empresas Pesquisadas

\begin{tabular}{|c|c|c|c|}
\hline LOTEAMENTOS & $\begin{array}{c}\text { QUANTIDADE DE LOTES } \\
\text { VENDIDOS }\end{array}$ & TEMPO DE ATUAÇÃO & TEMPO DE REGISTRO \\
\hline LOTEAMENTO A & 350 & 3 ANOS & 02 anos \\
\hline LOTEAMENTO B & 98 & 5 ANOS & 01 ano \\
\hline LOTEAMENTO C & 433 & 4 ANOS & 02 nos \\
\hline LOTEAMENTO D & 55 & 1 ANO & 01 ano \\
\hline
\end{tabular}

Fonte: Dados da Pesquisa.

Os dados do quadro I apontam que as empresas pesquisadas embora jovens na cidade com média de atuação de 01 a 05 anos tiveram a preocupação de fugir da informalidade a fim de proporcionar a seus clientes e parceiros maior confiabilidade nos serviços oferecidos. Fato este bastante importante visto que para muitas pessoas investir em um lote pode significar um sonho em se obter uma moradia.

\section{METOdOLOGIA}

Um trabalho científico se desenvolve por meio de uma inquietação, de uma curiosidade que um pesquisador tenha e que queira desvendar; que no âmbito deste trabalho é denominado 
de problema de pesquisa. Estes problemas, no entanto, são geralmente desvendados por meio de métodos sistemáticos que lhes proporcionem o alcance dos resultados desejados, ou seja, eles são desvendados com base em uma pesquisa. Para Andrade, $(2003$, p. 121) "Pesquisa é o conjunto de procedimentos sistemáticos, baseado no raciocínio lógico, que tem por objetivo encontrar soluções para problemas propostos, mediante a utilização de métodos científicos".

Neste tópico são abordados os procedimentos metodológicos utilizados no desenvolvimento da pesquisa em questão, enfatizando a natureza da pesquisa, a abordagem adotada, o instrumento para coleta de dados, além da delimitação do universo pesquisado.

A pesquisa utilizada neste trabalho é de caráter descritivo, uma vez que procura descrever, conforme os objetivos adotados, quais os fatores que influenciam os altos índices de endividamento e/ou inadimplência no setor imobiliário da cidade de Toritama - PE, bem como as características dos pesquisados.

Silva, (2003) enfatiza que uma pesquisa tem caráter descritivo quando busca a descrição das características de determinada população ou fenômeno, estabelecendo relações entre as variáveis.

Embora os estudos descritivos dêem margem à explicação de causa e efeito dos fenômenos analisados, (Oliveira, 1997); neste trabalho, buscou-se apenas expor as características sociais e financeiras, bem como as razões que levaram ou levam os proprietários de lotes a endividar-se, não tendo compromisso, portanto, em explicar o fenômeno descrito.

Neste sentido, foram utilizados tanto dados primários, neste caso adquiridos em campo, ou seja, no local da ocorrência do fenômeno; quanto dados secundários que foram obtidos através de pesquisas bibliográficas. Assim, conforme lembra Martins, (2000, p. 45) "São denominados secundários os dados já coletados, que se encontram organizados em arquivos, banco de dados, anuários estatísticos, relatórios etc. Em contraste, os dados primários são aqueles colhidos diretamente na fonte".

Quanto à forma de abordagem, os procedimentos metodológicos apresentam-se como indutivos. Pois como explica Gil (1999), o raciocínio indutivo parte do particular e coloca a generalização como um produto posterior ao trabalho de coleta de dados particulares. Este autor ainda afirma que neste método parte-se da observação de fatos ou fenômenos cujas causas se desejam conhecer procurando em seguida compará-los com a finalidade de descobrir as relações entre eles, procedendo-se por fim a generalização.

Esta pesquisa corresponde a um muticaso, que como lembra Gil (2009) proporciona evidências inseridas em diferentes aspectos, concorrendo para a elaboração de uma pesquisa de melhor qualidade. Ou seja, o muticaso corresponde a uma pesquisa mais elaborada onde se estuda em detalhes mais de uma variável. Neste trabalho buscou-se detalhar não só o perfil dos compradores de lotes, mas também a situação econômica e financeira destes, além dos fatores que ocasionam endividamento/ inadimplência nos quatro loteamentos pesquisados.

A coleta dos dados primários foi feita por meio de um questionário que segundo Gil, (1999, p. 128): “O questionário corresponde a uma técnica de investigação composta por um número mais ou menos elevado de questões apresentadas por escrito às pessoas, tendo por objetivo o conhecimento de opiniões, crenças, sentimentos, interesses, expectativas, situações vivenciadas etc." O questionário utilizado apresenta-se como estruturado composto por 
questões fechadas, onde buscou-se extrair informações essenciais ao trabalho baseada nos objetivos propostos no capítulo primeiro. Estas informações em princípio seriam tratadas apenas de forma quantitativa (predomínio de perguntas fechadas), no entanto, com o intuito de obter informações mais individualizadas colocou-se a opção outros em algumas questões, a fim de que os indivíduos pudessem externar sua opinião caso esta não se fizesse presente dentre as alternativas apresentadas.

O questionário está composto de duas etapas: Na primeira buscou-se obter informações sobre as características pessoais e financeiras dos respondentes. A segunda, no entanto, foi estruturada com base nos prospectos de Kahneman e Tversky (1979), onde buscou-se verificar se os vieses otimismo e excesso de confiança influenciam nas decisões financeiras dos indivíduos analisados. Esta etapa foi estruturada com base na escala de likert que conforme lembra Martins, (2000) corresponde a um conjunto de itens apresentados em forma de afirmações, no qual se pede aos sujeitos que externem suas opiniões, escolhendo um dos cinco, ou sete pontos de uma escala. As alternativas de respostas expostas na escala indicarão o quanto se está de acordo ou não com tal afirmação.

Estes questionários foram aplicados pelos pesquisadores durante dias alternados do mês de novembro diretamente com o público - alvo ao passo que estes se dirigiam até o escritório dos loteamentos pesquisados e nos próprios loteamentos com o porta-a-porta. Contudo buscouse não interferir nem induzir nas respostas dadas.

Cabe ressaltar, porém, que foram aplicados pré-testes com os proprietários de lotes durante a construção do questionário definitivo. Percebendo-se então, a necessidade de ajustes como mudança na linguagem antes contida e no volume de informações. A partir de então, buscou-se adequá-lo da melhor forma possível para que ficasse de acordo com os objetivos propostos na pesquisa e com o entendimento dos pesquisados.

De acordo com (ROESCH, 1999, p. 138) "Uma população é um grupo de pessoas ou empresas que interessa entrevistar para o propósito específico de um estudo".

Nesta pesquisa o universo está composto de 936 (Novecentos e Trinta e Seis) lotes vendidos e pertencentes aos 04 loteamentos analisados.

O propósito da amostragem é estabelecer um subconjunto representativo do universo pesquisado (ROESCH, 1999).

Neste trabalho será utilizada a amostra não probabilística, por acessibilidade e/ou conveniência, já que o universo pesquisado é bastante amplo sofrendo influência do fator limitador tempo. Sendo assim, a amostra fora composta por 200 (Duzentas) pessoas, as quais responderam ao questionário aplicado.

A análise dos dados foi feita por meio de métodos estatísticos, onde será atribuído uma numeração para cada variável pesquisada a fim de facilitar na mensuração do resultado, ou seja, para respostas binárias (com duas alternativas para respostas) serão atribuídos, por exemplo, o numeral 0 para resposta Sim e 01 para a resposta Não. Para questões com um número maior de alternativas de respostas a numeração será aumentada seguindo uma seqüência começando pelo numeral 01 (um), 02 (dois), 03(três)...; até que todas as alternativas fiquem enumeradas.

Para as questões apresentadas através do escalonamento tipo Likert, também serão utilizados o método estatístico para a apuração dos dados, onde para cada variável analisada, 
será medido o grau de concordância/discordância exposto na escala, que cada afirmação obteve. No entanto, já que se optou pela utilização de procedimentos estatísticos (que trata de estimativas) admitir-se-á certa margem de erro.

A representação dos dados obtidos estará disposta por meio de tabelas, pois como enfatiza Andrade, (2003, p. 155) "A tabela é um meio muito eficaz de expor os resultados obtidos, pois facilita a compreensão e a interpretação dos dados, permitindo não só a apreensão global, mas também o relacionamento entre eles".

\section{APRESENTAÇÃO DOS RESULTADOS}

Os resultados apresentados visam atender aos objetivos específicos. Estes são representados através de tabelas e gráficos.

Inicialmente busca-se identificar aspectos de perfil da população investigada, em seguida serão levantados dados como renda, gastos e propensão ao endividamento, logo após através do escalonamento de Likert, será verificado se os indivíduos sofrem influência dos vieses cognitivos otimismo e excesso de confiança.

A população do estudo é formada por proprietários de lotes da cidade de Toritama - PE. O perfil dos entrevistados pode ser visualizado nas tabelas 01 e 02.

Tabela 01 - Perfil dos entrevistados segundo as variáveis: gênero, faixa etária, estado civil, e escolaridade.

\begin{tabular}{|c|c|c|c|}
\hline VARIAVEIS & ALTERNATIVAS & FREQUÊNCIA & PERCENTUAL \\
\hline \multirow{2}{*}{ GENÊRO } & Masculino & 120 & $60 \%$ \\
\hline & Feminino & 80 & $40 \%$ \\
\hline \multirow{5}{*}{ FAIXA ETÁRIA } & Até 20 anos & 12 & $6 \%$ \\
\hline & De 21 À 30 Anos & 84 & $42 \%$ \\
\hline & De 31 À 40 Anos & 60 & $30 \%$ \\
\hline & De 41 À 50 Anos & 32 & $16 \%$ \\
\hline & Mais 50 Anos & 12 & $6 \%$ \\
\hline \multirow{5}{*}{ ESTADO CIVIL } & solteiro(a) & 143 & $72 \%$ \\
\hline & casado(a) com companheiro (a)/relação estável (sem filhos) & 12 & $6 \%$ \\
\hline & casado(a) com companheiro (a)/relação estável (com filhos) & 33 & $17 \%$ \\
\hline & Separado/divorciado & 12 & $6 \%$ \\
\hline & outros & 0 & $0 \%$ \\
\hline \multirow{6}{*}{ ESCOLARIDADE } & Nível primário (1a a 4a séries) & 64 & $32 \%$ \\
\hline & 2ㅇ grau completo & 23 & $12 \%$ \\
\hline & Nível Secundário (5a a 8 séries) & 93 & $47 \%$ \\
\hline & Nível Superior incompleto (Faculdade) & 3 & $2 \%$ \\
\hline & Nível Superior completo (Faculdade) & 6 & $3 \%$ \\
\hline & Outros & 11 & $6 \%$ \\
\hline
\end{tabular}

Fonte: Pesquisa de Campo

Conforme tabela 01 verifica-se que $60 \%$ do universo estudado pertence ao gênero masculino, e $40 \%$ ao gênero feminino, identifica-se também uma população jovem onde $72 \%$ da amostra vai da faixa etária dos 21 aos 40 anos idade. A tabela acima especifica ainda que $72 \%$ são solteiros.

O Grau de Escolaridade predominante dos entrevistados foi o nível secundário (5a a 8 séries) com índice de $47 \%$, comprova-se o baixo nível de escolaridade dos pesquisados, pois para o segundo grau tem-se $12 \%$ e superior completo $3 \%$. 
Tabela 02 - Perfil dos entrevistados segundo as variáveis grupo familiar, renda familiar, renda pessoal e fonte de renda pessoal.

\begin{tabular}{|c|c|c|c|}
\hline VARIAVEIS & ALTERNATIVAS & FREQUÊNCIA & PERCENTUAL \\
\hline \multirow{4}{*}{ GRUPO FAMILIAR } & 1 & 69 & $35 \%$ \\
\hline & 2 a 3 & 84 & $42 \%$ \\
\hline & 4 a 6 & 27 & $14 \%$ \\
\hline & mais de 6 & 20 & $10 \%$ \\
\hline \multirow{6}{*}{ RENDA FAMILIAR } & até $\mathrm{R} \$ 1.860,00$ & 172 & $86 \%$ \\
\hline & $\mathrm{R} \$ 1.861,00$ a $\mathrm{R} \$ 2.7900,00$ & 20 & $10 \%$ \\
\hline & $\mathrm{R} \$ 2.791,00$ a $\mathrm{R} \$ 3.720,00$ & 8 & $4 \%$ \\
\hline & $\mathrm{R} \$ 3.721,00$ a $4.650,00$ & 0 & $0 \%$ \\
\hline & $4.651,00$ a $5.580,00$ & 0 & $0 \%$ \\
\hline & acima de $R \$ 5.580,00$ & 0 & $0 \%$ \\
\hline \multirow{6}{*}{ RENDA PESSOAL } & até $\mathrm{R} \$ 1.395,00$ & 188 & $94 \%$ \\
\hline & de $1.396,00$ a $R \$ 2.325,00$ & 8 & $4 \%$ \\
\hline & de $2.326,00$ a $3.255,00$ & 4 & $2 \%$ \\
\hline & de $R \$ 3.256,00$ a $4.185,00$ & 0 & $0 \%$ \\
\hline & de $R \$ 4.186,00$ a $R \$ 5.115,00$ & 0 & $0 \%$ \\
\hline & acima de $\mathrm{R} \$$ 5.116,00 & 0 & $0 \%$ \\
\hline \multirow{5}{*}{ FONTE RENDA PESSOAL } & Mesada & 4 & $2 \%$ \\
\hline & Aposentadoria & 4 & $2 \%$ \\
\hline & Pensão & 0 & $0 \%$ \\
\hline & Salário & 88 & $44 \%$ \\
\hline & Outros & 104 & $52 \%$ \\
\hline
\end{tabular}

Através dos percentuais acima apresentados, percebe-se que das famílias entrevistadas, $86 \%$ possui apenas $\mathrm{R} \$ 1.860,00$ (um mil, oitocentos e sessenta reais) de renda familiar, sendo a maioria das residências compostas com 02 a 03 pessoas, e dividindo esta renda por 2,5 pessoas temos uma média de $\mathrm{R} \$ \mathbf{7 4 4 , 0 0}$ (Setecentos e quarenta e quatro reais) por pessoa. Esse número mostra uma população pertencente a uma classe social média a baixa.

Para o item fonte de renda pessoal, percebe-se que o padrão se repete, onde $94 \%$ dos pesquisados afirmaram que sua renda pessoal não ultrapassa $\mathrm{R} \$ 1.395,00$ (Um mil Trezentos e Noventa e cinco Reais). Dentre as fontes de rendas especificadas no questionário a maioria dos entrevistados selecionou o item "outras fontes", com 52\% das respostas. Este resultado remete ao índice considerável de comércio informal que a cidade de Toritama apresenta. A segunda fonte de renda citada foi salário com $44 \%$.

Tabela 03 - Perfil financeiro dos entrevistados segundo as variáveis gastos e como gastar.

\begin{tabular}{c|l|c|c}
\hline VARIAVEIS & \multicolumn{1}{|c|}{ ALTERNATIVAS } & FREQUÊNCIA & PERCENTUAL \\
\hline \multirow{4}{*}{ GASTOS } & Gastos domésticos & 108 & $54 \%$ \\
\cline { 2 - 4 } & Gastos com amigos & 0 & $0 \%$ \\
\cline { 2 - 4 } & Gastos com familiares & 22 & $11 \%$ \\
\cline { 2 - 4 } & Gastos consigo & 58 & $29 \%$ \\
\cline { 2 - 4 } & Outros & 38 & $6 \%$ \\
\hline \multirow{4}{*}{ COMO GASTAR } & Gasto mais do que ganho & 72 & $36 \%$ \\
\cline { 2 - 4 } & Gasto menos do que ganho & 8 & $4 \%$ \\
\cline { 2 - 4 } & Gasto muito mais do que ganho & 6 & $3 \%$ \\
\cline { 2 - 4 } & Gasto muito menos do que ganho & 76 & $38 \%$ \\
\cline { 2 - 4 } & Gasto igual ao que ganho & Fonte: Pesquisa de campo
\end{tabular}


No quesito gastos, percebe-se que 54\% apontam gastar mais com o lar (gastos domésticos), $29 \%$ enfatizam gastarem consigo e $6 \%$ apontam a opção outros. Através destes percentuais verifica-se que embora a população pesquisada seja jovem não existiu nenhum percentual para a opção gastos com amigos o que dar a entender que a renda de cada indivíduo é imprescindível para o orçamento familiar.

Para o item como gastar, $38 \%$ enfatizam que gastam igual ao que ganham $36 \%$ menos do que ganham e $19 \%$ mais do que ganham.

Tabela 04 - Perfil financeiro dos entrevistados

\begin{tabular}{c|l|c|c}
\hline \multicolumn{1}{c|}{ VARIAVEIS } & \multicolumn{1}{|c|}{ ALTERNATIVAS } & FREQUÊNCIA & PERCENTUAL \\
\hline \multirow{4}{*}{ CARTÃO DE CRÉDITO } & Não & 121 & $61 \%$ \\
\cline { 2 - 4 } & Sim, um cartão & 44 & $22 \%$ \\
\cline { 2 - 4 } & Sim, dois cartões & 12 & $6 \%$ \\
\cline { 2 - 4 } & Sim, três cartões & 15 & $8 \%$ \\
\cline { 2 - 4 } & sim, mais de três cartões & 8 & $4 \%$ \\
\hline \multirow{4}{*}{ CONTA-CORRÊNTE } & Sim & 48 & $24 \%$ \\
\cline { 2 - 4 } & Não & 152 & $76 \%$ \\
\hline \multirow{4}{*}{ POUPAR DINHEIRO } & Sempre & 48 & $24 \%$ \\
\cline { 2 - 4 } & Algumas vezes & 48 & $24 \%$ \\
\cline { 2 - 4 } & Freqüentemente & 12 & $6 \%$ \\
\cline { 2 - 4 } & Raramente & 48 & $24 \%$ \\
\cline { 2 - 4 } & Nunca & 34 & $22 \%$ \\
\hline & Sempre & 60 & $18 \%$ \\
\cline { 2 - 4 } & Algumas Vezes & 4 & $2 \% \%$ \\
\cline { 2 - 4 } & Freqüentemente & 52 & $26 \%$ \\
\cline { 2 - 4 } & Raramente & Fonte: Pesquisa de campo \\
\cline { 2 - 4 } & Nunca & & $28 \%$ \\
\hline
\end{tabular}

A tabela 04 mostra um baixo índice para a utilização de cartões de crédito, onde $61 \%$ dos entrevistados não possuem cartão crédito, $22 \%$ possui apenas um cartão, $6 \%$ possuem dois cartões, e $8 \%$ possui três cartões. Maior índice, porém, que no requisito conta bancária onde $76 \%$ população não possui conta corrente.

No quesito poupar dinheiro, houve um equilíbrio entre as opções sempre, raramente e algumas vezes, todas apresentaram índice de $24 \%$.

No item seu rendimento costuma sobrar, $30 \%$ dos respondentes enfatizaram que sobra algumas vezes, $26 \%$ raramente sobra, $24 \%$ nunca sobra, $18 \%$ sempre sobra e $2 \%$ frequentemente sobra recursos financeiros mensalmente.

Analisando estes itens percebe-se uma correlação entre a baixa incidência de uso de cartão de crédito e conta corrente com os rendimentos dos pesquisados. 
Tabela 05 - Perfil dos entrevistados pela quantidade de lotes adquiridos e objetivo de compra do terreno.

\begin{tabular}{c|l|c|c}
\hline \multirow{2}{*}{ VARIAVEIS } & \multicolumn{1}{c|}{ ALTERNATIVAS } & $\begin{array}{c}\text { FREQUÊNCI } \\
\text { A }\end{array}$ & $\begin{array}{c}\text { PERCENTU } \\
\text { AL }\end{array}$ \\
\hline \multirow{3}{*}{$\begin{array}{c}\text { OBJETIVO ADQUIRIR } \\
\text { TERRENO }\end{array}$} & Para uma moradia segura e tranqüila & 122 & $61 \%$ \\
\cline { 2 - 4 } & $\begin{array}{l}\text { Para vender o imóvel quando houver uma valorização } \\
\text { significante }\end{array}$ & 24 & $12 \%$ \\
\cline { 2 - 4 } & Fez o investimento no imóvel por falta de opções na cidade & 4 & $2 \%$ \\
\cline { 2 - 4 } & Considera um bom investimento & 38 & $19 \%$ \\
\cline { 2 - 4 } & Outros & 12 & $6 \%$ \\
\hline \multirow{2}{*}{ LOTES } & 01 Lote & 160 & $80 \%$ \\
\cline { 2 - 4 } & 02 Lotes & 24 & $12 \%$ \\
\cline { 2 - 4 } & 03 Lotes & 12 & $6 \%$ \\
\cline { 2 - 4 } & Mais de 03 lotes & 4 & $2 \%$ \\
\hline
\end{tabular}

Neste quesito, a maioria dos pesquisados $80 \%$ enfatizam só possuírem 01 lote, onde a grande maioria (61\%) destaca que adquiriram o lote para possuir sua moradia segura.

Tabela 06 - Perfil financeiro dos entrevistados segundo as variáveis, dívidas, fatores de endividamento, situação financeira e período de gastos.

\begin{tabular}{|c|c|c|c|}
\hline VARIAVEIS & ALTERNATIVAS & FREQUÊNCIA & PERCENTUAL \\
\hline \multirow{7}{*}{ PERÍODO MAIS GASTO } & Não tem período específico & 125 & $63 \%$ \\
\hline & Dia dos pais/ mães /crianças & 0 & $0 \%$ \\
\hline & Situações emergenciais & 12 & $6 \%$ \\
\hline & Natal / final de ano & 48 & $24 \%$ \\
\hline & Festas e casamentos & 0 & $0 \%$ \\
\hline & Carnaval & 15 & $8 \%$ \\
\hline & Outros & 0 & $0 \%$ \\
\hline \multirow{2}{*}{ DÍVIDAS } & Sim & 160 & $80 \%$ \\
\hline & Não & 40 & $20 \%$ \\
\hline \multirow{6}{*}{ FATORES ENDIVIDAMENTO } & Desemprego & 25 & $13 \%$ \\
\hline & Problemas Saúde Familiar & 29 & $15 \%$ \\
\hline & Aquecimento do Mercado (Tempo bom, Tempo ruim & 67 & $34 \%$ \\
\hline & Falta planejamento Financeiro & 56 & $28 \%$ \\
\hline & Empréstimo do Nome & 14 & $7 \%$ \\
\hline & Outros & 9 & $5 \%$ \\
\hline \multirow{3}{*}{ SITUAÇAO FINANCEIRA } & Extremamente satisfeito & 64 & $32 \%$ \\
\hline & Mais ou menos Satisfeito & 108 & $54 \%$ \\
\hline & Extremamente Insatisfeito & 28 & $14 \%$ \\
\hline
\end{tabular}

Consoante da amostra $54 \%$ enfatiza estarem mais ou menos satisfeitos com sua situação financeira. Devido à baixa renda familiar, no entanto, $80 \%$ apresentam problemas com dividas e informa que não há um período específico para gastar (63\%) e que a sazonalidade de mercado (34\%), a falta de planejamento financeiro (28\%), problemas de saúde na família (15\%) e desemprego (13\%) são respectivamente os fatores principais para o seu endividamento. 
A seguir, a análise sobre a influência dos vieses comportamentais otimismo e excesso de confiança nas decisões financeiras dos indivíduos.

Afirmativa I - O que eu ganho é suficiente e de acordo com o meu esforço.

\begin{tabular}{|c|c|c|c|c|c|c|c|c|c|c|}
\hline \multirow{2}{*}{ AFIRMATIVA I } & \multicolumn{2}{|c|}{1} & \multicolumn{2}{|c|}{2} & \multicolumn{2}{|c|}{3} & \multicolumn{2}{|c|}{4} & \multicolumn{2}{|c|}{5} \\
\cline { 2 - 11 } & 52 & $26 \%$ & 4 & $2 \%$ & 36 & $18 \%$ & 32 & $16 \%$ & 76 & $38 \%$ \\
\hline
\end{tabular}

A maioria dos pesquisados concordou com a afirmação acima citada, onde 38\% concordam totalmente; percebe-se, portanto, que há certo grau de satisfação dos indivíduos pesquisados no tocante ao seu esforço/salário.

Afirmativa II - Eu não tenho muito hábito de planejar as coisas, se algo de bom tem de acontecer, acontecerá.

\begin{tabular}{|c|c|c|c|c|c|c|c|c|c|c|}
\hline \multirow{2}{*}{ AFIRMATIVA II } & \multicolumn{2}{|c|}{1} & \multicolumn{2}{|c|}{2} & \multicolumn{2}{|c|}{3} & \multicolumn{2}{|c|}{4} & \multicolumn{2}{c|}{5} \\
\cline { 2 - 11 } & 56 & $28 \%$ & 12 & $6 \%$ & 36 & $18 \%$ & 40 & $20 \%$ & 56 & $28 \%$ \\
\hline
\end{tabular}

Para esta afirmativa, $28 \%$ não se mostram muito otimistas quanto ao fator sorte; pois acreditam que é necessário planejar as coisas para que elas possam obter êxito. Em contrapartida a mesma quantidade de respondentes, $28 \%$, acreditam que uma meta ou um objetivo traçado pode acontecer sem que haja a necessidade de planejamento. Percebe-se, portanto, que há um equilíbrio entre a razão e a emoção, uns são mais confiantes e otimistas e outros mais racionais e realistas.

Afirmativa III - A maioria das vezes os meus problemas são devidos a acontecimentos ruins.

\begin{tabular}{|c|c|c|c|c|c|c|c|c|c|c|}
\hline \multirow{2}{*}{ AFIRMATIVA III } & \multicolumn{2}{|c|}{1} & \multicolumn{2}{|c|}{2} & \multicolumn{2}{|c|}{3} & \multicolumn{2}{|c|}{4} & \multicolumn{2}{|c|}{5} \\
\cline { 2 - 11 } & 64 & $32 \%$ & 16 & $8 \%$ & 56 & $28 \%$ & 12 & $6 \%$ & 52 & $26 \%$ \\
\hline
\end{tabular}

Para esta afirmativa, $32 \%$ dos pesquisados não acreditam que os seus problemas surjam em ocasião de acontecimentos ruins. (mostrando-se, portanto, otimistas), Contudo, 26\% acreditam na influência de aspectos negativos. Percebe-se então que há quase um equilíbrio em relação ao fator otimismo e excesso de confiança nesta afirmativa em ocasião da pouca diferença apresentada, apenas $6 \%$, entre os que se mostram mais otimistas e os que são menos otimistas.

Afirmativa IV - As coisas realmente boas que acontecem comigo são resultado de muita sorte.

\begin{tabular}{|c|c|c|c|c|c|c|c|c|c|c|}
\hline \multirow{2}{*}{ AFIRMATIVA IV } & \multicolumn{2}{|c|}{1} & \multicolumn{2}{|c|}{2} & \multicolumn{2}{|c|}{3} & \multicolumn{2}{|c|}{4} & \multicolumn{2}{|c|}{5} \\
\cline { 2 - 10 } & 52 & $26 \%$ & 20 & $10 \%$ & 52 & $26 \%$ & 16 & $8 \%$ & 60 & $30 \%$ \\
\hline
\end{tabular}


Analisando esta afirmativa percebe-se que $26 \%$ dos entrevistados não estimam pela sorte e sim pela realidade/consequências dos seus esforços "pensam com a razão", no entanto, 30\% optam pelo oposto, concordando plenamente que são pessoas que possuem bastante sorte. Nesta afirmativa há novamente quase um equilíbrio entre as pessoas que se sentem otimistas e confiantes das que não se sentem tão otimistas e confiantes, o que dá a entender que os vieses otimismo e excesso de confiança têm influência em apenas uma parcela dos entrevistados, não em sua totalidade.

Afirmativa V - Sou confiante sobre a minha capacidade de gerir meus recursos financeiros.

\begin{tabular}{|c|c|c|c|c|c|c|c|c|c|c|}
\hline \multirow{2}{*}{ AFIRMATIVA IV } & \multicolumn{2}{|c|}{1} & \multicolumn{2}{|c|}{2} & \multicolumn{2}{|c|}{3} & \multicolumn{2}{|c|}{4} & \multicolumn{2}{|c|}{5} \\
\cline { 2 - 10 } & 16 & $8 \%$ & 8 & $4 \%$ & 36 & $18 \%$ & 36 & $18 \%$ & 104 & $52 \%$ \\
\hline
\end{tabular}

Nesta afirmativa, 52\% dos entrevistados dizem ser confiantes e ter capacidade de gerir seus recursos financeiros.

COMENTÁRIO GLOBAL: Através dos resultados apresentados nas afirmativas acima, percebe-se que há influência dos vieses otimismo e excesso de confiança em apenas uma parcela dos indivíduos pesquisados; não em sua totalidade, já que na maioria das respostas apresentadas, existia praticamente um equilíbrio entre as pessoas que se sentiam confiantes e otimistas sobre si mesmas e sobre o acaso, daquelas que não se sentiam tão confiantes e otimistas e sim mais realistas e racionais.

\section{CONCLUSÕES}

Com base nas questões norteadoras deste estudo, as seguintes conclusões são apresentadas.

8.1 Traçar o perfil dos indivíduos analisados (Proprietários de lotes).

Diante da pesquisa efetuada pode-se definir que a maioria dos proprietários de lotes são:

$>$ Do gênero masculino;

$>$ Média de idade de 21 a 40 anos;

$>$ Solteiros;

$>$ Baixo grau de escolaridade;

> Praticantes de religião, com predominância da religião católica;

$>$ Composição familiar formada por 2 a 3 pessoas;

$>$ Renda familiar até $\mathrm{R} \$ 1.860,00$ (Um mil Oitocentos e Sessenta Reais)

$>$ Renda pessoal até $\mathrm{R} \$ 1.395,00$.

8.2 Perfil Financeiro dos entrevistados:

A maioria gasta igual ao que ganha; 
> São poucos os que possuem conta-corrente ou cartão de crédito;

$>$ Possuem mais gastos domésticos, do que gastos consigo mesmo ou com outros;

$>$ Raramente seu rendimento sobra;

$>$ Raramente consegue poupar dinheiro.

\subsection{Comentário item Perfil dos proprietários de lotes:}

Através dos dados acima apresentados, pode-se concluir que estes indivíduos pertencem a uma classe social menos favorecida, onde mal conseguem cobrir suas despesas essenciais. Esta realidade comprova a tese de Katona (1975), precursor dos estudos sobre endividamento na ótica econômica/psicológica, que enfatiza a falta de recursos financeiros como uma das razões que explicam o endividamento de um indivíduo.

8.4 Descrever os principais fatores que influenciam o endividamento e geram inadimplência no setor analisado.

Dentre os fatores citados, 04 foram os mais enfatizados como:

> Sazonalidade de mercado;

$>$ Falta de planejamento financeiro;

$>$ Problemas de saúde familiar;

$>$ Desemprego.

Além disso, $80 \%$ dos entrevistados enfatizam possuírem dívidas, não tendo um período específico que gaste mais e se consideram mais ou menos satisfeitos com sua situação financeira.

A partir desses dados pode-se verificar a forte influência dos fatores externos na composição do endividamento destes indivíduos, esta realidade comprova os estudos de Kotler e keller (2006), Ferreira (2009), Márcia Tolli.

Ainda fazendo eco aos estudos da pesquisadora Márcia Tolli; através do perfil dos pesquisados e dos fatores considerados essenciais na composição de seu endividamento, verifica-se que se enquadram como um endividado Passivo, que é aquele que realmente passou por algum imprevisto, seja doença, desemprego, emprego precário... e por isso encontra-se endividado.

\subsection{Verificar a influência de fatores comportamentais, de perfil e externos na composição do endividamento:}

Constatou-se com a pesquisa realizada forte influência de fatores externos na composição do endividamento como já enfatizado no item anterior, quanto ao fator perfil, percebe-se que apesar da maioria da população ser jovem, com perfeita capacidade intelectual, grande parte não possuem o segundo grau completo, visto que, a cultura da cidade sempre foi dar mais ênfase ao trabalho que aos estudos como bem constatou o Sebrae (2003) em sua pesquisa sobre o projeto de desenvolvimento do pólo de confecções do agreste pernambucano. Esta falta de conhecimentos leva o indivíduo a possuir empregos que mais dependem do aquecimento da economia (sazonalidade de mercado) do que do seu intelecto, o que justifica o fator sazonalidade de mercado ter sido mencionado como um dos principais fatores de endividamento. 
8.6 Verificar até que ponto os vieses otimismo e excesso de confiança afetam as decisões financeiras dos indivíduos endividados:

Para este quesito, verificou-se que os vieses otimismo e excesso de confiança influenciam apenas uma parcela dos entrevistados, visto que o número de pessoas que se consideravam otimistas e confiantes quase se equipararam com os que se mostravam mais realistas e racionais.

\section{LIMITAÇÃO DA PESQUISA}

Uma das principais limitações encontradas para a coleta dos dados foi o tempo, a disponibilidade dos pesquisados e das pesquisadoras. Salienta-se também, que o fator tempo foi a principal limitação desta pesquisa em seu âmbito geral, tendo em vista uma série de fatores correlacionados como, trabalho, família, distância. No entanto, buscou-se otimizá-lo da melhor maneira possível a fim de que os resultados obtidos pudessem alcançar a eficácia desejada.

\section{SUGESTÕES PARA FUTURAS PESQUISAS}

Como sugestões para pesquisas futuras pode-se enfatizar:

- Aplicar esta pesquisa em outro segmento econômico,

- Verificar a influência de outros vieses comportamentais;

- Fazer um aprofundamento nesta pesquisa através do cruzamento dos dados coletados, a fim de verificar a correlação entre eles.

\section{REFERÊNCIAS}

ALMEIDA, M. I. R. DE; GLIGIO, E. M. O planejamento Estratégico no Ramo Imobiliário: Um estudo exploratório. Artigo do III SEMEAD. Disponível em http://www.ead.fea.usp.br/Semead/ 3semead/pdf/Adm_Geral/Art104.PDF. Acessado em $02 / 11 / 2009$

ANDRADE, Maria Margarida de. Introdução à metodologia do trabalho científico: elaboração de trabalhos na graduação. 5. ed. São Paulo: Atlas, 2003.

BELHOTT, R. V.; OLIVEIRA, V.; OLIVEIRA NETO, J. D.. Os Estilos Cognitivos na formação de estudantes em duas áreas de formação acadêmica: Ciências contábeis e Engenharia da Produção. Qualis Nac A. In: ANPCONT - Qualis Nacional A, 2008, Blumentau. // congresso ANPCONT, 2008.

BERNAL, M. C. C. Especulação Imobiliária e Turismo no Nordeste. Artigo. Fortaleza - CE. Disponível em http://3537610629035068022-a-metrowiki-net-s-sites.googlegroups.com/a/ metrowiki.net/observat-rio-das-metr-poles-workshop-fortaleza/trabalhos-apresentados/Es pecula\%C3\%A7\%C3\%A3o_Imobili\%C3\%A1ria_e_Turismo_no_Nordeste.pdf?attachauth=ANo Y7crGIn5-c2wW00i43Jcdlmn_E_6jvKvMwkQ0xQ5qtpbs2cF16LFCdQRL2gAloznOpET_ZwRO NVBk6-KhlcQZ2cdniMTyEUQyg6G2DuQYPxjja5uf3VqSYkuuHkIB6eDJeRrJemg2wLdq8WY3 phs7fZToEod3kmdcYJSxuxM6EtrUPrMU6la4SaQOco_crvHGtLkayTjOYuHGfiftZI2ZOxxAFpuuhP 29zT3gB9IA9yIRKP8eKzGJ12Qo6V4U-hPOsa2yoGCUcN3BjOBShihlfbR42ZPMSn8gaJjVnKGm illp2XRtMSpT24L00W8mREz39GtJLhtPYHK5zo3TEXFm9rXtyH_w\%3D\%3D\&attredirects=0. Acesso em 02/11/2009.

BORSATO, Jaluza Maria Lima Silva et al.. Otimismo e excesso de confiança: Um estudo do perfil 
comportamental dos indivíduos, à luz das finanças comportamentais. In: XII SEMEAD, 2009, São Paulo. Empreendedorismo e Inovação, 2009.

; PIMENTA, Daiana Paula; RIBEIRO, Karém Cristina de Souza. Finanças Comportamentais: Um Estudo Descritivo sobre o viés de Aversão à perda no Processo decisório. In: XII SEMEAD, 2009, São Paulo. Empreendedorismo e Inovação, 2009.

COSTA, Getúlio José Moreira da. Pós - modernidade, política e educação. In: Globalização e a perda da identidade do estado - nação, 2004. Disponível em: <http://www.angelfire.com/sk/holgonsi/getulio.html>. Acesso em 22/09/2009.

FERREIRA, Vera Rita. Porque o endividamento das pessoas tem crescido?; 2007. Disponível em: www.clubedosendividados.com.br. Acesso em Setembro 2009.

GIL, Antônio Carlos. Métodos e Técnicas de pesquisa social. 5. ed. São Paulo: Atlas, 1999.

GIL, Antônio Carlos. Como Elaborar Projetos de Pesquisa. 4. ed. São Paulo: Atlas, 2009.

GONÇALVES, J C. A especulação Imobiliária na formação de loteamentos urbanos: Um estudo de caso. Dissertação de Mestrado. Campinas, São Paulo. Dezembro, 2002. Dissertação disponível em http://libdigi.unicamp.br/document/?code=vtls000295271. Acesso em 02/11/2009

KOTLER, P.; KELLER, K. L. Administração de Marketing. 12 ed. São Paulo: Pearson 2006.

MALLMANN, Estela Isabel et al. Finanças Pessoais: Análise dos gastos e da propensão ao endividamento em estudantes de Administração. In: XII SEMEAD, 2009, São Paulo. XII SEMEAD: Empreendedorismo e Inovação, 2009.

MARIUZZO, PATRÍCIA. Mercado Imobiliário vive bom momento. Disponível em https://www.comciencia.br/comciencia/handler.php?section=8\&edicao $=25 \& i d=285 \&$ tipo $=0$ Acesso em 02/11/2009

MARTINS, Gilberto de Andrade. Manual para elaboração de Monografias e Dissertações. 3 ed., São Paulo: Atlas, 2002.

MILANEZ, Daniel Y. Finanças Comportamentais. 2003. 53p. Dissertação (Mestrado em Administração). Programa de Pós Graduação em Administração de Empresas. Universidade de São Paulo, 2001.

XIMENES, Sérgio, 1954. Minidicionário Ediouro da Língua portuguesa - 2a ed. Reform. - São Paulo: Ediouro, 2000.

OBSERVATÓRIO DO ENDIVIDAMENTO DOS CONSUMIDORES. Endividamento e sobreendividamento das famílias: Conceitos e estatísticas para sua avaliação. Centro de Estudos Sociais da Faculdade de Economia da Universidade de Coimbra, Fev/2002.

OLIVEIRA, Silvio Luiz de. Tratado de metodologia científica. Projetos de pesquisa, TGI, TCC, Monografias, Dissertações e Teses. 2 ed., São Paulo: Pioneira, 1997.

PAIVA, Cláudio César; QUINTO JR., Luiz de Pinedo. Estabilidade Macroeconômica, novos Investimentos e o Mercado imobiliário Brasileiro; VII Seminário de LARES - 25 e 26 de Outubro, São Paulo, 2007.

POLO atacadista se vestiu de jeans. Diário de Pernambuco. Recife, p. E2, 22/01/2004.

ROESCH, Sylvia Maria Azevedo. Projetos de Estágio e de Pesquisa em Administração: Guia para 
estágios, trabalhos de conclusão, dissertações e estudos de caso. 2 ed., São Paulo: Atlas, 1999.

SEBRAE. Projeto de Desenvolvimento do pólo de confecções do Agreste Pernambucano. Disponível em: http://www.sebrae-pe.com.br. Acesso em 02/11/2009.

SANDRONI, Paulo. “Novíssimo Dicionário de Economia”. Edição, 1999.

SILVA, Antônio Carlos ribeiro de. Metodologia da pesquisa aplicada à contabilidade: orientações de estudos, projetos, relatórios, monografias, dissertações, teses. São Paulo: Atlas, 2003.

SOUZA, C. A.; KAYO, Eduardo Kazuo; PUSCH, A. C.; YU, A. S. O.; Teoria da perspectiva (prospect theory) de Kahneman e Tversky: estudo empírico com alunos de graduação em administração. In: VI SEMEAD, 2003, São Paulo. Anais...,2003.

ZERRENNER, Sabrina Arruda. Estudo sobre as razões para o endividamento da população de baixa renda. 2007. Dissertação (Mestre em ciências Administrativas) - Universidade de São Paulo, São Paulo, 2007. 